\title{
Iron Deficiency Anemia Prevalence at First Stroke or Transient Ischemic Attack
}

\author{
Melanie D. Dubyk, Robert T. Card, Susan J. Whiting, Carol A. J. Boyle, \\ Stanley H. Zlotkin, Phyllis G. Paterson
}

\begin{abstract}
Background: Iron deficiency anemia (IDA) has been implicated in the etiology of transient ischemic attack and ischemic stroke. This study aimed to: 1) document IDA prevalence in patients $\geq 65$ years of age admitted to hospital with transient ischemic attack or first ischemic stroke, and 2) investigate dietary intake as a predictor of iron status. Methods: Ninety-four patients were enrolled. An algorithm containing values for hemoglobin, ferritin, total iron binding capacity, transferrin saturation, and serum transferrin receptor measured at admission was used to identify IDA. Usual dietary intake was assessed with the Clue II food frequency questionnaire. Results: Prevalence estimates were $6.4 \%$ for IDA, $2.1 \%$ for iron deficiency without anemia, and $6.4 \%$ for anemia from other causes. IDA prevalence was significantly higher than published National Health and Nutrition Examination Survey III (NHANES III) estimates for gender-specific age groups $\geq 70$ years (One-Sample Proportion Test; males $\mathrm{p}=0.038$ [ $\mathrm{n}=37$ ]; females $\mathrm{p}=0.002$ [ $\mathrm{n}=44]$ ). A comparison of IDA prevalence against selected controls from the NHANES III database yielded an odds ratio (OR) of 6.3, 95\% confidence interval (CI) 0.8 to 53.7, which was not statistically significant (Fisher's Exact Test; $n=94 ; p=0.118$ ). Multivariate linear regression analysis of dietary intake with indicators of iron status $(n=58)$ revealed only iron supplements $(p=0.013)$ and heme iron intake $(\mathrm{p}=0.038)$ as negative predictors of total iron binding capacity $(\mathrm{p}<0.05)$. Conclusions: These findings support the initiation of a prospective case control study to investigate IDA as a risk factor for ischemic stroke in elderly patients.
\end{abstract}

RÉSUMÉ: Prévalence de la carence en fer au moment du premier accident vasculaire cérébral ou du premier épisode d'ischémie cérébrale transitoire. Contexte : L'anémie ferriprive (AFP) a été impliquée dans l'étiologie de l'ischémie cérébrale transitoire (ICT) et de l'accident vasculaire cérébral ischémique (AVCI). Le but de cette étude était de : 1) documenter la prévalence de l'AFP chez les patients de plus de 65 ans admis à l'hôpital pour une ICT ou un premier épisode d'AVCI et 2) d'évaluer la diète de ces patients comme élément de prédiction du statut en fer. Méthode : Quatrevingt-quatorze patients ont été inclus dans l'étude. Un algorithme incluant les valeurs d'hémoglobine, de ferritine, de capacité totale de fixation du fer, de saturation de la transferrine et du récepteur de la transferrine sérique mesurés au moment de l'admission à l'hôpital a été utilisé pour identifier l'AFP. L'apport alimentaire a été évalué au moyen du questionnaire de fréquence Clue II. Résultats : Les estimés de prévalence étaient de 6,4\% pour l'AFP, $2,1 \%$ pour le déficit en fer sans anémie et $6,4 \%$ pour l'anémie due à une autre cause. La prévalence de l'AFP était significativement plus élevée que celle publiée dans NHANES III, estimée pour l'âge et le sexe, pour les individus de 70 ans et plus [test de proportion; hommes $\mathrm{p}=0,038$ ( $\mathrm{n}=37$ ) ; femmes $p=0,002(n=44)$ ]. La comparaison entre la prévalence de l'AFP dans notre groupe de patients et celle observée dans certains groupes témoins tirés de la base de données de NHANES III a fourni un rapport de cotes (RC) de 6,3 (IC à 95\%:0,8 à 53,7) ce qui n'était pas significatif au point de vue statistique (méthode exacte de Fischer ; $\mathrm{n}=94 ; \mathrm{p}=0,118$ ). L'analyse de régression linéaire multivariée de l'apport alimentaire avec les indicateurs de statut en fer $(\mathrm{n}=58)$ a montré que seulement la prise de suppléments de fer $(\mathrm{p}=0,013$ et l'apport en fer hémique $(\mathrm{p}=0,038)$ étaient des facteurs de prédiction négatifs de la capacité de liaison du fer $(\mathrm{p}<0,05)$. Conclusion : Selon ces observations, il serait justifié de procéder à une étude cas-témoin pour examiner si l'AFP est un facteur de risque de l'AVCI chez les patients âgés.

Can J Neurol Sci. 2012; 39: 189-195

Iron deficiency anemia (IDA) has been proposed as an etiological factor for ischemic stroke. There is considerable evidence for this for pediatric transient ischemic attack (TIA) and ischemic stroke ${ }^{1-7}$, and IDA has emerged in a recent case control study as a significant risk factor for stroke in otherwise healthy young children ${ }^{7}$. In adult ischemic stroke, however, it is less well-established that IDA confers risk. This hypothesis was first supported by a series of case reports linking IDA to thrombocytosis and stroke, implicating reactive thrombocytosis as a contributing mechanism ${ }^{8-10}$. A follow-up study to the First National Health and Nutrition Examination Survey (NHANES I) identified a significant U-shaped relationship between transferrin saturation and stroke in white women 45-74 years of age $^{11}$, suggesting an increased risk for stroke at both low and high levels of circulating iron. Lower serum iron concentration, an indicator of reduced iron transport and negative iron balance, has been reported as a significant predictor of stroke in elderly

\footnotetext{
From the College of Pharmacy and Nutrition (MDD, SJW, PGP), Division of Hematology (RTC), Division of Neurology (CAJB), Department of Medicine, University of Saskatchewan; Stroke Prevention Clinic, Saskatoon Health Region, Saskatoon, Saskatchewan (CAJB); The Hospital for Sick Children, Departments of Pediatrics, Nutritional Sciences, and Public Health Sciences (SHZ), University of Toronto, Toronto, Ontario, Canada.

Received February 10, 2011. Final Revisions Submitted September 13, 2011. Correspondence to: Phyllis Paterson, College of Pharmacy and Nutrition, University of Saskatchewan, 110 Science Place, Saskatoon, Saskatchewan, S7N 5C9, Canada.
} 
subjects ${ }^{12}$. Ekblom et al ${ }^{13}$ also identified increased stroke risk in the highest quartile of total iron binding capacity, a parameter that rises with iron deficiency.

The elderly are at highest risk for stroke and associated disability $^{14}$ and also have high rates of anemia ${ }^{15}$. Anemia estimates in the elderly range from $4.9 \%$ to $15.1 \%$ in females and $3.3 \%$ to $14.4 \%$ for males ${ }^{15-18}$. For IDA specifically, population prevalence estimates in the United States, England, and Italy are $1.1-4.1 \%$ for elderly males and $1-1.3 \%$ for females ${ }^{16,17,19,20}$. Unfortunately, there are no current population-based Canadian data, since the last national survey results on elderly Canadians is now nearly 40 years-old ${ }^{21}$.

The diagnosis of IDA in elderly stroke patients is difficult because it requires differentiating between IDA and the anemia of chronic disease (ACD) ${ }^{17}$. Bone marrow aspirate, the gold standard for determining iron status, is invasive and often unreliable when performed in a routine clinical laboratory ${ }^{22}$. Serum ferritin, although commonly used to assess iron stores, also rises with chronic infection, inflammation, liver disease, and malignancy ${ }^{22,23}$. Serum transferrin receptor (sTfR) concentration has been under-utilized in the elderly, yet it is a valuable measurement that increases with iron deficiency after storage iron is depleted ${ }^{24}$. Serum transferrin receptor values continue to rise as iron deficiency progresses to the anemia stage (reviewed $\mathrm{in}^{22,24}$ ) and can both distinguish between IDA and ACD and identify iron deficiency coexisting with $\mathrm{ACD}^{25-31}$. Values for STfR remain normal in inflammatory conditions and $\mathrm{ACD}^{32}$, offering a particular advantage for assessing iron ( $\mathrm{Fe}$ ) status during the inflammatory response to stroke $\mathrm{e}^{33}$.

The role of diet as an independent contributor to iron status in the elderly is also uncertain. Nutritional status is often compromised by multiple mechanisms that impact on dietary intake, such as impaired functional and cognitive status, multiple medical conditions and medications, poor oral health, poverty, changes in taste and smell, and dysphagia ${ }^{34}$. Gastrointestinal blood loss, non-steroidal anti-inflammatory drugs, anticoagulants, genitourinary disease, or frequent blood drawings can also contribute to IDA in aged individuals ${ }^{35}$. Positive associations have been reported between iron status and dietary factors such as iron supplements ${ }^{20,36}$, heme iron (found in meat, poultry and fish) ${ }^{20}$, vitamin $C^{20,37}$, protein ${ }^{37}$, and alcohol ${ }^{17,20}$. However, the strength of these associations is limited by varying accuracy among the different indicators of iron status that have been employed. The relationship between dietary intake and iron status has not been studied in stroke patients.

Despite the intriguing evidence that IDA may increase risk for ischemic stroke and TIA, there are no reported prevalence estimates for IDA in elderly stroke patients. Thus, our objective was to employ a rigorous algorithm that included measurement of sTfR to determine the prevalence of IDA in a series of patients 65 years-of-age or older admitted to hospital with TIA or first presentation of ischemic stroke. Prevalence data for IDA were compared with existing published figures for free-living elderly. We also investigated whether previous dietary intake was a predictor of iron status for patients newly admitted with stroke or TIA.

\section{Methods}

\section{Subjects}

Data were obtained prospectively from elderly patients $\geq 65$ years of age $(n=94)$ admitted sequentially to the Neurology service at Royal University Hospital, Saskatoon, Saskatchewan between May 23 and December 23, 1999. These patients were diagnosed with first ischemic stroke or TIA clinically by a neurologist. Exclusion criteria were intracerebral or subarachnoid hemorrhage, stroke due to a brain tumour, or previous known history of stroke. Consent was obtained from the patient or next-of-kin. Ethics approval was obtained from the University of Saskatchewan Advisory Committee on Ethics in Human Experimentation.

Medical charts were reviewed in order to document major risk factors for stroke (age, gender, race, hypertension, smoking status, carotid stenosis, atrial fibrillation, previous TIA, diabetes mellitus, family history, dyslipidemia, and cardiac disease) and potential medical causes of IDA (gastrointestinal blood loss, non-steroidal anti-inflammatory drugs or anticoagulant use, and genitourinary disease).

\section{Laboratory analysis}

Blood samples were obtained within 24 hours of admission. Serum samples were stored at $-70^{\circ} \mathrm{C}$ until analysis for sTfR using an enzyme immunoassay kit and manufacturer reference range (Ramco Laboratories, Houston, Texas). The remaining laboratory tests (serum ferritin, serum iron, transferrin saturation, total iron binding capacity (TIBC), white blood cell count, red blood cell count, hemoglobin, hematocrit, mean corpuscular volume, mean corpuscular hemoglobin, mean corpuscular hemoglobin concentration, red blood cell distribution width, platelet count, and mean platelet volume) were conducted using the methodology and reference ranges of the Department of Laboratory Medicine, Saskatoon Health Region.

\section{Classification of iron status}

Based on the algorithm shown in the Figure, patients were classified into the following groups: a) IDA, b) occult iron deficiency, c) ACD, d) IDA coexisting with ACD, and e) other anemia.

\section{Comparison of IDA prevalence with published estimates}

We undertook a preliminary comparison of our IDA prevalence figures against a published population estimate. Because of the lack of Canadian data for comparison, the IDA prevalence in our study group was compared with results from the NHANES III Study, which was selected as the largest comprehensive population-based study of Fe status relevant to our data collection timeline and subject age. This was a six year study (1988-1994) conducted by the National Center for Health Statistics, Centers for Disease Control and Prevention to assess the health and nutritional status of the civilian noninstitutionalized population of the United States ${ }^{19}$. In the Third National Health and Nutrition Examination Survey (NHANES III), IDA was identified by two or more abnormal values for free erythrocyte protoporphyrin, transferrin saturation, or ferritin ${ }^{19}$. 


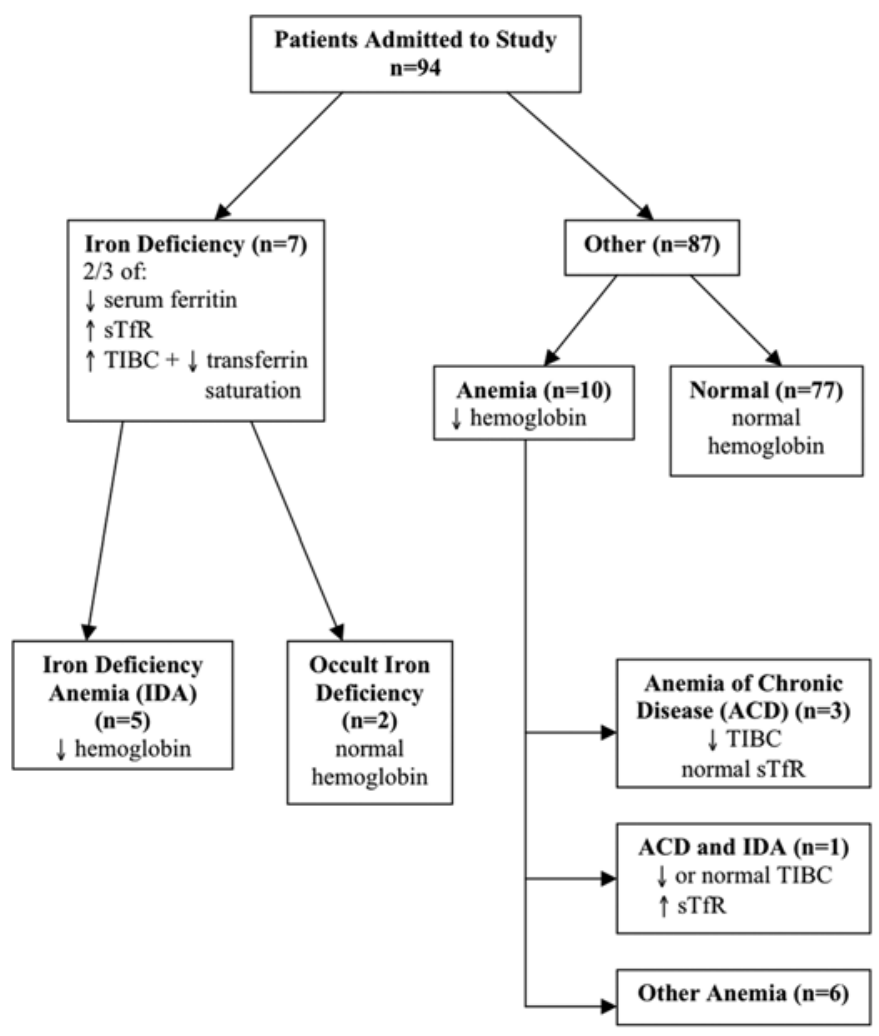

Figure: The number of cases of IDA and other anemia subtypes identified by the iron status classification algorithm. Cases in each category are shown within brackets.

Two methods were used for comparison: 1) First, our prevalence estimates for males and females were compared with the published prevalence figures from NHANES III for freeliving elderly subjects $(n=3,067)^{19}$. As the latter data were only specified for the age groups of 50-69 years and $\geq 70$ years, IDA prevalence was calculated for those subjects from our study who were $\geq 70$ years $(n=81)$. 2) Secondly, we made a small refinement in the comparison by using a limited case control approach to compare our IDA prevalence figure with that from 94 age- and gender-matched controls (with black and Hispanic individuals excluded) from the NHANES III database ${ }^{38}$ who resided in areas in the Midwestern U.S.A. with populations $<1,000,000$ and did not have a previous history of stroke. Although it was not possible to conduct a comprehensive case control study that matched subjects for stroke risk factors, this secondary analysis did enable selection of NHANES III individuals who were better controls with respect to age, gender, ethnicity, geographical location, and environment (rural or smaller city size and altitude).

\section{Dietary intake}

Usual dietary intake was assessed by interviewing the patient and/or surrogate source during the hospital stay in order to complete a CLUE II Health Habits and History (modified Block) Questionnaire, a 63-item food frequency questionnaire. This questionnaire records usual diet over the past year and has been directly validated against antioxidant status $^{39}$ and indirectly validated for iron ${ }^{40}$. The questionnaires were produced, scanned, and analyzed by Block Dietary Data Systems (Berkeley, California).

\section{Statistical analysis}

Statistics were performed using SPSS Statistics 17.0 software, with all results considered significant at $\mathrm{p}<0.05$.

For the first comparison of IDA prevalence estimates, we utilized the One-Sample Proportion Test with continuity correction $^{41}$. For the second comparison of IDA prevalence between the two groups, an odds ratio and $95 \%$ confidence interval were calculated, and Fisher's Exact Test was used to test the hypothesis that the odds ratio=1. Fisher's Exact Test was chosen since two cells had an expected count less than $5^{41}$. Similarly, Fisher's Exact Test was chosen to determine whether other potential causes of IDA, that is, non-steroidal antiinflammatory drugs, anticoagulants, gastrointestinal disease, or genitourinary disease, were associated with the presence of IDA. Chi-square analysis was used to test whether there were differences in the proportion of cases diagnosed with stroke versus TIA by gender.

Multivariate analysis was used to examine associations between dietary variables that would be expected to influence outcome measures of iron status. Initial bivariate analysis was used to examine the association between single predictor variables (age, body mass index, gender, kilocalories, protein, dietary iron, supplemental iron, total iron, dietary vitamin $\mathrm{C}$, supplemental vitamin $\mathrm{C}$, total vitamin $\mathrm{C}$, fiber, heme iron, and alcohol), and outcome measures of iron status (sTfR, total iron binding capacity, hemoglobin, and presence or absence of IDA). Those variables found to be significant predictors at $p<0.20$ were considered in subsequent model building. Forward stepwise selection procedure was used and stepwise criteria for entry were set as follows: probability of $\mathrm{F}$ to enter $\leq 0.20$, probability of $\mathrm{F}$ to remove $\geq 0.30$.

\section{Results}

\section{Sample demographics}

The overall consent rate was 92\%. Demographic characteristics are shown in Table 1 and demonstrate an equal number of females and males with $62.8 \%$ of the sample $\geq 75$ years of age. Eighty-four percent $(n=79)$ of subjects presented with stroke, and $16 \%$ presented with TIA $(n=15)$. These diagnoses were not significantly different by gender $\left(\mathrm{X}^{2}=0.079\right.$, $\mathrm{p}>0.05)$. The presence of risk factors for stroke as identified by chart review is also shown in Table 1.

\section{Prevalence of IDA}

The number of cases identified for IDA, iron deficiency without anemia, IDA co-existing with ACD, ACD, and other anemias is found in the Figure. The overall prevalence of IDA in our sample of stroke and TIA patients was $6.4 \%$, accounting for $40 \%$ of all cases of anemia identified. Only one of these six individuals had IDA co-existing with ACD. Earlier stage iron deficiency without anemia was present in $2.1 \%$ of the sample. Anemia from other causes was identified in $6.4 \%$ of the patients. Table 2 contains descriptive statistics for key hematological data. 
Table 1: Demographic and risk factor characteristics of subjects at study enrolment

\begin{tabular}{|c|c|c|c|}
\hline Characteristic & Frequency & Total $^{1}$ & Percent \\
\hline \multicolumn{4}{|l|}{ Age (years) } \\
\hline $65-74$ & 35 & 94 & 37.2 \\
\hline $75+$ & 59 & 94 & 62.8 \\
\hline \multicolumn{4}{|l|}{ Gender } \\
\hline Male & 47 & 94 & 50.0 \\
\hline Female & 47 & 94 & 50.0 \\
\hline \multicolumn{4}{|l|}{ Other risk factors } \\
\hline Hypertension $^{2}$ & 61 & 94 & 64.9 \\
\hline Smoking & 18 & 94 & 19.1 \\
\hline Carotid Stenosis & 26 & 71 & 36.6 \\
\hline Atrial Fibrillation & 18 & 94 & 19.1 \\
\hline Previous TIA & 20 & 94 & 21.3 \\
\hline Diabetes Mellitus & 28 & 94 & 29.8 \\
\hline Family History of Stroke & 4 & 94 & 4.3 \\
\hline Elevated Cholesterol $^{3}$ & 33 & 60 & 55.0 \\
\hline Cardiac Disease $^{4}$ & 48 & 94 & 51.1 \\
\hline
\end{tabular}

${ }^{1}$ For whom data was available by chart review. ${ }^{2}$ History of hypertension, hypertension medication use or diagnosis at admission. ${ }^{3}$ Serum total cholesterol $>5.2 \mathrm{mmol} / \mathrm{L}$, history of dyslipidemia or lipid lowering medication. ${ }^{4}$ History of coronary artery disease, angina, myocardial infarction, cardiomyopathy, congestive heart failure, mitral stenosis/calcification, or left ventricular hypertrophy.

Table 2: Summary of hematological parameters used to identify IDA

\begin{tabular}{lcccc}
\hline & Gender & n & Mean (SD) & Median \\
Serum Transferrin Receptor $(\mu \mathrm{g} / \mathrm{ml})^{1}$ & F & 45 & $4.8(2.6)$ & 4.0 \\
Serum Ferritin $(\mu \mathrm{g} / \mathrm{L})^{2}$ & M & 46 & $4.9(3.6)$ & 3.9 \\
& F & 47 & $90(71)$ & 83 \\
Total Iron Binding Capacity $(\mu \mathrm{mol} / \mathrm{L})^{3}$ & M & 47 & $210(402)$ & 57 \\
& F & 47 & $56(11)$ & 52 \\
Transferrin Saturation $(\%)^{4}$ & M & 47 & $50(11)$ & 19 \\
Hemoglobin $(\mathrm{g} / \mathrm{L})^{5}$ & F & 47 & $21(12)$ & 23 \\
& M & 47 & $25(13)$ & 133 \\
\hline
\end{tabular}

Reference Ranges: ${ }^{12} 29-8.3 \mu \mathrm{g} / \mathrm{ml} ;{ }^{2} 20-120 \mu \mathrm{g} / \mathrm{L}$ (female), 20-400 $\mu \mathrm{g} / \mathrm{L}$ (male); ${ }^{3} 34-51 \mu \mathrm{mol} / \mathrm{L}$ (female), $41-63$ $\mu \mathrm{mol} / \mathrm{L}$ (male); ${ }^{4} 14-51 \%$ (female), $25-56 \%$ (male); ${ }^{5} 110-160 \mathrm{~g} / \mathrm{L}$ (female), 135-180 g/L (male). 


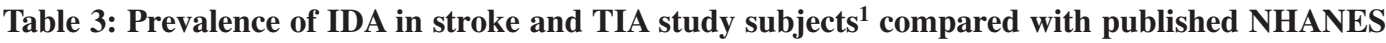 III prevalence rates}

\begin{tabular}{lcccc}
\hline & & & & p-value \\
Gender & Iron and Stroke/TIA Study & NHANES III & 2.07 & 0.038 \\
Male & $8.1 \%$ & $2 \%$ & 3.11 & 0.002 \\
Female & $6.8 \%$ & $1 \%$ & & \\
\hline
\end{tabular}

${ }^{1}$ Includes subjects $\geq 70$ years ( $n=37$ males, $n=44$ females). ${ }^{2}$ One-Sample Proportion Test with continuity correction.

Table 3 shows comparison of IDA prevalence in the stroke and TIA patients $(\mathrm{n}=81)$ with NHANES III prevalence figures for gender-specific age groups $\geq 70$ years. The prevalence of IDA in our study was significantly higher than that found in NHANES III for both men and women (males $\mathrm{p}=0.038$; females $\mathrm{p}=0.002)$. The second limited case-control comparison $(\mathrm{n}=94)$ yielded a similar difference in IDA prevalence between our subjects and the reference group to that obtained with the first analysis (Table 4). This secondary analysis yielded an odds ratio of 6.3 , which was not statistically significant $(\mathrm{p}=0.118)$.

\section{Predictors of IDA}

Nonsteroidal anti-inflammatory drug use $(\mathrm{p}=0.414)$, anticoagulant use $(\mathrm{p}=0.681)$, gastrointestinal disease $(\mathrm{p}=1.00)$, and genitourinary disease $(p=0.501)$ were not significantly associated with the presence of IDA.

Dietary information was available for only 58 patients $(62 \%$ of the sample). Results from multivariate linear regression analysis of dietary intake with indicators of iron status revealed few significant associations. Gender emerged as a highly significant predictor of hemoglobin $(\mathrm{p}<0.01)$, and supplemental iron $(p=0.013)$ and heme iron intake $(p=0.038)$ were negative predictors of total iron binding capacity $(\mathrm{p}<0.05)$.

\section{Discussion}

This prospective study is the first to document the prevalence of IDA in elderly patients at hospital admission for TIA or first stroke. Due to the lack of consensus criteria for investigating IDA in the elderly, we developed a powerful classification scheme that included the specificity of STfR values for identifying tissue iron deficiency while limiting the influence of any single variable. We describe a prevalence of IDA of $6.4 \%$, with IDA accounting for $40 \%$ of all cases of anemia. Our patient sample appears to be relatively representative of the larger population, given the high consent rate $(92 \%)$ and the similarity of our subjects' baseline characteristics to those of the Registry of the Canadian Stroke Network ${ }^{42}$. Specifically, profiles were similar for the risk factors of hypertension, smoking and male gender, whereas the prevalence of diabetes and dyslipidemia was higher in our study, possibly due to the older subject age. A smaller proportion of our cases $(15 \%)$ presented with TIA compared to $33 \%$ for the Stroke Registry, and it is likely that TIA was underrepresented in our study because such patients are not always admitted to hospital.

Our preliminary analyses suggest that IDA may be more prevalent in elderly patients newly admitted for TIA or first stroke than in the general free-living elderly population. The first approach, a gender-specific comparison of our prevalence figures with those published for free-living subjects 70 years of age and older from the NHANES III Study ${ }^{19}$, demonstrated a higher prevalence of IDA in the stroke and TIA patients for both genders. This comparison has limitations since an unknown number of the elderly reference group would have had a previous stroke. The NHANES III sample also included individuals from across the United States, so factors such as altitude, ethnicity, and lifestyle, including diet, may have differed from our Canadian prairie province-based sample. The second comparison, in which we selected more similar control subjects from this database ${ }^{38}$, yielded a similar absolute difference in IDA prevalence between our sample and the reference group. An odds ratio calculation revealed that our firsttime stroke or TIA patients were 6.3 times more likely to have IDA. Although not statistically significant, this odds ratio suggests that the finding may be clinically important; the wide confidence interval suggests that the study was underpowered to

Table 4: Prevalence of IDA in stroke and TIA study subjects compared with NHANES III controls ${ }^{1}$

\begin{tabular}{|c|c|c|c|c|}
\hline & $\begin{array}{l}\text { IDA present } \\
\text { Frequency (\%) }\end{array}$ & $\begin{array}{c}\text { IDA absent } \\
\text { Frequency }(\%)\end{array}$ & $\begin{array}{l}\text { Odds ratio } \\
\text { (95\% CI) }\end{array}$ & p-value ${ }^{2}$ \\
\hline $\begin{array}{l}\text { Iron and Stroke/ TIA } \\
\text { study }\end{array}$ & $6(6.4 \%)$ & $88(93.6 \%)$ & \multirow{2}{*}{$\begin{array}{c}6.3 \\
(0.8,53.7)\end{array}$} & \multirow{2}{*}{0.118} \\
\hline NHAANES III & $1(1.1 \%)$ & $93(98.9 \%)$ & & \\
\hline
\end{tabular}

${ }^{1}$ Age and gender-matched control subjects (with black and Hispanic individuals excluded) without history of previous stroke who resided in areas in the Midwestern U.S.A. with populations $<1,000,000(n=94)$. ${ }^{2}$ Fisher's Exact Test. 
make this comparison. Finally, these conclusions are guarded for both comparisons, since our algorithm for detecting IDA was more rigorous than the methodology used in the NHANES III Study. In particular, sTfR measurements have superior predictive value in the presence of the anemia of chronic disease.

The experimental design utilized was not intended to establish IDA as a cause of stroke. However, the intriguing results do suggest that a comprehensive prospective case control study matching subjects for all major stroke risk factors should be undertaken to further investigate whether IDA increases risk for stroke in elderly individuals. Our prevalence estimate would provide valuable baseline data for calculating the sample size required for adequate power. This undertaking is especially compelling given the recent finding that healthy young children presenting with vaso-occlusive stroke are ten times more likely to have IDA than those without stroke ${ }^{7}$. While it is acknowledged that the etiology of pediatric stroke differs from that of the adult, IDA has now been accepted as an etiological factor for stroke in children ${ }^{43}$.

We also found a prevalence of $2.1 \%$ sub-clinical iron deficiency, which is characterized by iron storage depletion and tissue iron deficiency prior to the onset of anemia. While most studies on stroke risk have addressed IDA, there is insufficient evidence on underlying mechanisms to exclude sub-clinical iron deficiency as a possible risk factor for stroke. In fact, two epidemiological studies associated stroke risk with biochemical measures of early stage iron deficiency ${ }^{11,13}$. Several mechanisms have been proposed by which IDA could promote the development of stroke, including thrombocytosis ${ }^{4,8}$, altered erythrocyte deformability and blood flow, anemic hypoxia ${ }^{4}$ and endothelial dysfunction associated with inflammation ${ }^{44}$. Some of these mechanisms are altered by early stage iron deficiency, but unfortunately, none have been carefully investigated in the setting of stroke.

A secondary objective of our study was to examine the role of dietary intake as a predictor of iron status. Iron supplements and heme iron (the more readily absorbed form) emerged as significant negative predictors of total iron binding capacity, which increases with iron deficiency and reflects the iron binding potential of transferrin ${ }^{45}$. This is in agreement with previous reports of an inverse association of TIBC with iron supplements ${ }^{46}$. The lack of association with total dietary or nonheme iron is not surprising, since the latter is less well absorbed and more influenced by dietary promoters and inhibitors of iron absorption $^{47,48}$. Nonheme iron absorption can also be impaired by atrophic gastritis, which is common in elderly persons $\left(\right.$ reviewed $\mathrm{in}^{47}$ ). No dietary variable emerged from our study as a significant predictor of hemoglobin, the indicator of late-stage iron deficiency that declines when iron stores are depleted and circulating iron levels are depressed. Dietary inadequacies may not have been prolonged enough to affect hemoglobin levels. In contrast to others who documented inverse associations between sTfR and iron intake in younger subjects ${ }^{49,50}$, we found no associations between dietary variables and sTfR. Although these data suggest that dietary intake was not a major contributor to IDA in our patients, this conclusion is based on only 58 dietary analyses. Several medical conditions and medications are also known contributors to IDA in the elderly ${ }^{35}$. These factors did not appear to be critical in our patients since we found no associations between IDA and nonsteroidal anti-inflammatory drug or anticoagulant use, gastrointestinal disease or genitourinary disease. However, this conclusion is limited by the relatively small number of IDA cases.

An additional $6.4 \%$ of our patients presented with anemia that could not be explained by IDA or the anemia of chronic disease. Although our algorithm was not intended to identify the type of these anemias, such cases deserve further study since anemia of all causes has also been implicated as a precipitant of stroke and related mortality ${ }^{44,51-54}$. This does not preclude the possibility that subclinical iron deficiency or IDA confer added risk through specific mechanisms beyond anemic hypoxia.

In summary, the $6.4 \%$ prevalence of IDA documented in an elderly stroke and TIA group at hospital admission provides intriguing evidence to support a future case control study in elderly stroke patients. Further investigation should clarify whether IDA is a preventable cause of stroke in the elderly. The study of possible mechanisms for increased stroke risk in the setting of IDA is also warranted. Although our study has focused on IDA, other forms of anemia as well as early stage sub-clinical iron deficiency, should be further studied.

\section{ACKNOWLEDGEMENTS}

Funding for support of stroke research is gratefully acknowledged from the Heart and Stroke Foundation of Saskatchewan by PGP. Scholarship support was provided to MDD by the Scottish Rite Charitable Foundation and the University of Saskatchewan Hope Hunt Scholarship Fund.

\section{REFERENCES}

1. Ganesan V, Prengler M, McShane MA, Wade AM, Kirkham FJ. Investigation of risk factors in children with arterial ischemic stroke. Ann Neurol. 2003;53:167-73.

2. Saxena K, Ranalli M, Khan N, Blanchong C, Kahwash SB. Fatal stroke in a child with severe iron deficiency anemia and multiple hereditary risk factors for thrombosis. Clin Pediatr. 2005;44: 175-80.

3. Baptist EC, Castillo SF. Cow's milk-induced iron deficiency anemia as a cause of childhood stroke. Clin Pediatr. 2002;41:533-5.

4. Hartfield DS, Lowry NJ, Keene DL, Yager JY. Iron deficiency: a cause of stroke in infants and children. Pediatr Neurol. 1997;16: 50-3.

5. Bruggers CS, Ware R, Altman AJ, Rourk MH, Vedanarayanan V, Chaffee S. Reversible focal neurologic deficits in severe iron deficiency anemia. J Pediatr. 1990;117:430-2.

6. Ready WK, Lowry NJ. Anemia causing cerebral infarction in a child. Can Med Assoc J. 1989;140:303-4.

7. Maguire JL, deVeber G, Parkin PC. Association between irondeficiency anemia and stroke in young children. Pediatrics. 2007;120:1053-7.

8. Akins PT, Glenn S, Nemeth PM, Derdeyn CP. Carotid artery thrombus associated with severe iron-deficiency anemia and thrombocytosis. Stroke. 1996;27:1002-5.

9. Scoditti U, Colonna F, Ludovico L, Trabattoni G. Mild thrombocytosis secondary to iron-deficiency anemia and stroke. Riv Neurol. 1990; 60:146-7.

10. Alexander MB. Iron deficiency anemia, thrombocytosis, and cerebrovascular accident. South Med J. 1983;76:662-3.

11. Gillum RF, Sempos CT, Makuc DM, Looker AC, Chien C-Y, Ingram DD. Serum transferrin saturation, stroke incidence, and mortality in women and men: The NHANES I epidemiologic followup study. Am J Epidemiol. 1996;144:59-68.

12. Marniemi J, Alanen E, Impivaara O, et al. Dietary and serum vitamins and minerals as predictors of myocardial infarction and stroke in elderly subjects. Nutr Metab Cardiovas Dis. 2005;15: 188-97. 
13. Ekblom K, Hultdin J, Stegmayr B, et al. Iron stores and HFE genotypes are not related to increased risk of ischemic stroke. A prospective nested case-referent study. Cerebrovasc Dis. 2007; 24:405-11.

14. Hankey GJ, Jamrozik K, Broadhurst RJ, Forbes S, Anderson CS. Long-term disability after first-ever stroke and related prognostic factors in the Perth Community Stroke Study, 1989-1990. Stroke. 2002;33:1034-40.

15. Guralnik JM, Ershler WB, Schrier SL, Picozzi VJ. Anemia in the elderly: A public health crisis in hematology. Hematology Am Soc Hematol Educ Program. 2005:528-53.

16. Ferrucci L, Semba RD, Guralnik JM, et al. Proinflammatory state, hepcidin, and anemia in older persons. Blood. 2010;115:3810-6.

17. Tull KI, Hirani V, Ali A, Chua E, Mindell JS. Impact of different diagnostic thresholds and the anaemia-ferritin-transferrin receptor model on the prevalence of anaemia and impaired iron status in older people. Age Ageing. 2009;38:609-13.

18. Fleming DJ, Jacques PF, Tucker KL, Massro JM, D'Agostino RB, Wilson SPF. Iron status of the free-living, elderly Framingham Heart Study cohort: an iron-replete population with a high prevalence of elevated iron stores. Am J Clin Nutr. 2001;73: 638-46.

19. Looker AC, Dallman PR, Carroll MD, Gunter EW, Johnson CL. Prevalence of iron deficiency in the United States. J Am Med Assoc. 1997; 277:973-6.

20. Fleming DJ, Jacques PF, Dallal GE, Tucker KL, Wilson PWF, Wood RJ. Dietary determinants of iron stores in a free-living elderly population: The Framingham Heart Study. Am J Clin Nutr. 1998;67:722-33.

21. Health and Welfare Canada. Nutrition Canada National Survey. Ottawa: Health and Welfare Canada; 1973.

22. Cook JD. Diagnosis and management of iron-deficiency anaemia. Best Pract Res Clin Haematol. 2005;18:319-32.

23. Borch-Iohnsen B. Perspective. Determination of iron status: brief review of physiological effects on iron measures. Analyst. 1995;120:891-3.

24. Skikne BS. Serum transferrin receptor. Am J Hematol. 2008;83: $872-5$

25. Hanif E, Ayyub M, Anwar M, Ali W, Bashir M. Evaluation of serum transferrin receptor concentration in diagnosing and differentiating iron deficiency anaemia from anemia of chronic disorders. J Pak Med Assoc. 2005;55:13-6.

26. Baillie FJ, Morrison AE, Fergus I. Soluble transferrin receptor: a discriminating assay for iron deficiency. Clin Lab Haem. 2003; 25:353-7.

27. Bultink IEM, Lems WF, van de Stadt RJ, et al. Ferritin and transferrin receptor predict iron deficiency in anemic patients with rheumatoid arthritis. Arth Rheum. 2001;44:979-81.

28. Chua E, Clague JE, Sharma AK, Horan MA, Lombard M. Serum transferrin receptor assay in iron deficiency anaemia and anaemia of chronic disease in the elderly. QJ Med. 1999;92:587-94.

29. Punnonen K, Irjala K, Rajamäki A. Serum transferrin receptor and its ratio to serum ferritin in the diagnosis of iron deficiency. Blood. 1997;89:1052-7.

30. Pettersson T, Kivivuori SM, Siimes MA. Is serum transferrin receptor useful for detecting iron-deficiency in anaemic patients with chronic inflammatory diseases? Br J Rheumatol. 1994;33: $740-4$

31. Suominen P, Möttönen T, Rajamäki A, Irjala K. Single values of serum transferrin receptor and transferrin receptor ferritin index can be used to detect true and functional iron deficiency in rheumatoid arthritis patients with anemia. Arthritis Rheum. 2000;43:1016-20.

32. Ferguson BJ, Skikne BS, Simpson KM, Baynes RD, Cook JD. Serum transferrin receptor distinguishes the anemia of chronic disease from iron deficiency anemia. J Lab Clin Med. 1992;119: 385-90.

33. McCombe PA, Read SJ. Immune and inflammatory responses to stroke: good or bad? Int J Stroke. 2008;3:254-65.

34. Weddle DO, Fanelli-Kuczmarski M. Position of the American Dietetic Association: Nutrition, aging, and the continuum of care. J Am Diet Assoc. 2000;100:580-95.
35. Johnson MA, Fischer JG, Bowman BA, Gunter EW. Iron nutriture in elderly individuals. FASEB J. 1994;8:609-21.

36. Garry PJ, Hunt WC, Baumgartner RN. Effects of iron uptake on iron stores in elderly men and women: longitudinal and crosssectional results. J Am Coll Nutr. 2000;19:262-9.

37. Payette H, Gray-Donald K. Dietary intake and biochemical indices of nutritional status in an elderly population, with estimates of the precision of the 7-d food record. Am J Clin Nutr. 1991;54: 478-88.

38. U.S. Department of Health and Human Services. National Center for Health Statistics. Third National Health and Nutrition Examination Survey, 1988-1994, NHANES III Laboratory Data File (CD-ROM). Hyattsville (MD): Centers for Disease Control and Prevention; 1996.

39. Block G, Norkus E, Hudes M, Mandel S, Helzlsouer K. Which plasma antioxidants are most related to fruit and vegetable consumption? Am J Epidemiol. 2001;154:1113-8.

40. Block G, Hartman AM, Naughton D. A reduced dietary questionnaire: Development and vaidation. Epidemiology. 1990; $1: 58-64$

41. Altman DG. Practical statistics for medical research. London: Chapman and Hall; 1991.

42. Kapral MK, Silver FL, Richards JA, Lindsay P, Fang J, Shi HS: Registry of the Canadian Stroke Network. Progress Report 2001-2005. Toronto: Institute for Clinical Evaluative Sciences; 2005.

43. Pappachan J, Kirkham FJ. Cerebrovascular disease and stroke. Arch Dis Child. 2008;93:890-8.

44. Kim JS, Kang SY. Bleeding and subsequent anemia: a precipitant for cerebral infarction. Eur Neurol. 2000;43:201-8.

45. Lee GR, Herbert V. Nutritional factors in the function and production of erythrocytes. In: Lee GR, Foerster J, Lukens J, Paraskevas F, Greer JP, Rodgers GM, editors. Wintrobe's clinical hematology. 10th ed. Baltimore: Williams and Wilkins; 1999. p. 228-66.

46. Borch-Iohnson B, Meltzer HM, Stenberg V, Reinskou T, Trygg K. Bioavailability of daily low dose iron supplements in menstruating women with low iron stores. Eur J Clin Nutr. 1990; 44:29-34

47. Carmel R. Nutritional anemias and the elderly. Semin Hematol. 2008:45:225-34

48. Cooper MJ, Cockell KA, L'Abbé MR. The iron status of Canadian adolescents and adults: Current knowledge and practical implications. Can J Diet Pract Res. 2006;67:130-8.

49. Beguin JL, Grek V, Weber G, et al. Acute functional iron deficiency in obese subjects during a very-low energy all-protein-diet. Am J Clin Nutr. 1997;66:75-9.

50. Zhu YI, Haas JD. Response of serum transferrin receptor to iron supplementation in iron-depleted, nonanemic women. Am J Clin Nutr. 1998;67:271-5.

51. Hare GMT, Tsui AKY, McLaren AT, Ragoonanan TE, Yu J, Mazer CD. Anemia and cerebral outcomes: Many questions, fewer answers. Anesth Analg. 2008;107:1356-70.

52. Ani C, Ovbiagele B. Elevated red blood cell distribution width predicts mortality in persons with known stroke. J Neurol Sci. 2009;277:103-8

53. Kiyohara Y, Ueda K, Hasuo Y, et al. Hematocrit as a risk factor of cerebral infarction: long-term prospective population survey in a Japanese rural community. Stroke. 1986;17:687-92.

54. Gebreyohanns M, Adams RJ. Sickle cell disease: primary stroke prevention. CNS Spectr. 2004;9:445-9. 